\title{
Agendas for future Training Transfer Research: Pakistan's Perspective
}

\author{
Asif Ali Rahman* Mohammad Omar Shiddike \\ Faculty of Education, University of Regina, 3737 Wascana PKWY, Regina SK, S4P 2M9, Canada
}

This work was financed by Regina Public Interest Research Group and the Faculty of Graduate Study and Research of the University of Regina, Canada.

\section{Abstract}

Research on training transfer has been mostly conducted in developed countries. This paper is unique because it attempts to research training transfer from a developing country's perspective. This paper is about the origins, evolution, current state and trends in training transfer research and practice in Pakistani organizations. The paper begins with a discussion on education and training. It discusses the evolution of education and training in Pakistan and explains the four systems of education in Pakistan at the primary, high school, and college levels. Then, this paper explores the origins of training in Pakistan. While exploring the origins of training in Pakistan, this section gives a detailed account on the training and consulting industry of Pakistan. The paper concludes with suggestions for further research that would contribute in the fields of training transfer and human resource development.

Keywords: Training transfer, human resource development, education, Pakistan, management.

DOI: $10.7176 / \mathrm{DCS} / 9-4-06$

Publication date: April $30^{\text {th }} 2019$

\section{Introduction}

This paper is about the origins, evolution, current state and trends in training transfer research and practice in Pakistani organizations. Training transfer is defined as the degree to which trainees effectively apply the knowledge, skills, and attitudes gained in a training context to the job (Wexley and Latham 1981, Newstrom 1984). The paper is divided into three sections: introduction, training transfer in Pakistan, and to be continued .... The first section, introduction has three sub-sections: formal education vs. training, history and evolution of education in Pakistan, and the origins of training in Pakistan. The first section discusses the importance of understanding the difference between education and training, the history and evolution of education in Pakistan, including the four systems of education currently prevailing in the country, and the origins of training in Pakistan, including a detailed account of the training and consulting industry of Pakistan.

The second section, training transfer in Pakistan has two sub-sections: evolution of training transfer in Pakistan and current trends in training transfer research. The second section traces the evolution of training transfer in Pakistan. This section presents various examples in which training was conducted and training transfer (both positive and negative) occurred but the awareness of the concept of training transfer itself was missing. This section discusses the trends in training transfer research in Pakistan. This part not only explains the training transfer research conducted by various Pakistani researchers but also describes why the concept of training transfer is important.

The third and final section, to be continued ... is meant as a food for thought for readers. The title of this section implies that this section would elicit further research in the field and research on various areas discussed in this paper would continue. This section has two sub-sections: future research and summary and conclusions. This section identifies the gaps in training transfer research and practice in Pakistani organizations, offers some future research suggestions and a conclusion.

\subsection{Formal Education Vs. Training}

Formal education and training have close ties together. Perhaps, the relationship between formal education and training can best be explained by the following figure:

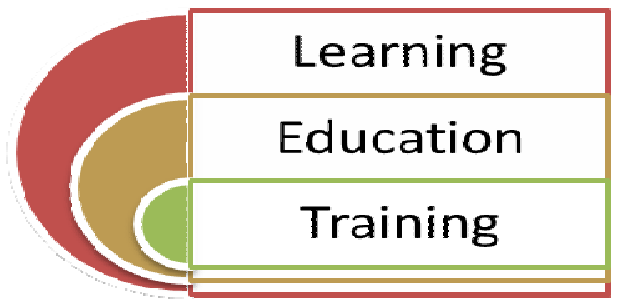

Fig. 1: Education Vs. Training 
Education and training contribute to individual's learning, the former being broad and knowledge-based while later being specific and skill-based. According to Tight (2003), "Education is what takes place in an educational institution". There is an interesting deficiency in the above-mentioned conceptualization of education which is that the above definition does not explain the quality of education. For example, we might define apples as something that grows on apple trees without giving due diligence to what apples really are. Therefore, this definition of education suggests a need for a conceptualization of specific skill-based training. In other words, as opposed to education, training might be defined as the acquisition of specific knowledge, skills, and attitudes towards a specific job (Baldwin, Ford et al. 2009). It can also be inferred from the above figure that training (acquisition of knowledge, kills, and attitudes) and training transfer (transfer of knowledge, skills, and attitudes acquired during a training to a job efficiency) depend upon the kind of general education the individual has attained. Therefore, an effective analysis of the origins, evolution, current state and trends in training transfer research in Pakistan involves an understanding of the history and evolution of education in Pakistan.

\subsection{History \& Evolution of Education in Pakistan}

Education and training in Pakistan are as old as the country itself. Pakistan came into being in 1947 and training in Pakistan began with the advent of National Education Conference held in 1947 (Bengali 1999). The National Education Conference was one of the first attempts in the field of education policy making and literacy in Pakistan. The purpose of the National Education Conference was to formulate the first education policy of the country, develop the first curriculum of primary (grade 5), high school (grade 10), and college (grade 12) education, and design a policy for introducing vocational training in the country to meet its skill needs. The conference started with a famous quote from the founder of Pakistan, Mohammad Ali Jinnah “... the importance of education and the type of education cannot be over-emphasized ... there is no doubt that the future of our State will and must greatly depend upon the type of education we give to our children, and the way in which we bring them up as future citizens of Pakistan ... we should not forget that we have to compete with the world which is moving very fast in this direction".

Unfortunately, the inspiring words of Mohammad Ali Jinnah were not remembered for long. Although the coming years witnessed the formulation of ten five-year national plans (1955-60, 1960-65, 1965-70, 1978-83, 1983-88, 1988-93, 1993-98, 1998-2003, and 2001-11), seven education policies (1951, 1970, 1979, 1992, 1998, 2009 and 2017), and five nation-wide literacy programs (1979, 1981, 1983, 1986, and 1990), turbulent domestic politics, volatile international relations, and vested interests of political parties and Pakistan military did not give the educational institutions and training ventures a chance to flourish. The five-year national plans, the education policies, and the literacy programs discussed vocational training for skill development, education, allocation of budget and resources for education and vocational training, and implementation of some mass literacy programs in the country (Hussain 1998, Bengali 1999, Shakoor, Azeem et al. 2011, Dildar, Saif et al. 2016, Chaudhry 2017).

Currently, four kinds of education systems exist in Pakistan. The first is the traditional education system called the 'Madrasas'. Madrasas teach a very narrow-minded version of Islam and not much education is taught in these schools. The teachings and concepts of madrasas are mostly based upon some misinterpretations of the Quran and Islam as a religion. Madrasas are not under government control since most of them are not even registered. Local clerics run madrasas in different villages and small cities as they deem appropriate. Although madrasas have mostly negative connotation attached to them locally and internationally, they do serve as providers of free shelter, free food, and free education for the homeless and poor classes of the society. They run mostly on donations from the local people (Sajjad 2013, Butt and Khalid 2017).

The second kind of education system is called the 'Urdu Medium'. Urdu Medium education system is a network of government schools scattered mostly in villages and remote small cities and towns of the country. Urdu medium schools start at class 1 (grade 1) and end at class 10 (grade 10). The entire education of children in these ten years is based on an obsolete curriculum and is taught by an untrained and insufficiently educated teaching staff. The medium of instruction in these schools is Urdu (Pakistan's national language) and English is taught only as a subject. Children who come out of these schools face immense difficulties in College (grade 11 and 12) and Pakistani universities where the medium of instruction is entirely English (Rahman 1997, Rahman 2010, Nelson 2018).

The third kind of education system is called the 'English Medium'. English Medium education system is a network of government schools available mostly in small cities and towns of the country. English medium schools start at class 1 (grade 1) and end at class 10 (grade 10). The entire English medium education of children in these ten years is also based on an obsolete curriculum and is taught by an untrained and insufficiently educated teaching staff. However, the medium of instruction in these schools is English. Although children graduating from these schools do not face language problems in college (grade 11 and 12), they face immense difficulties in universities since the universities are mostly based upon the current modern professional education prevalent in the rest of the world (Sarmad, Husain et al. 1989, Nasir and Nazli 2000, Rahman 2010). 
The fourth system of education is the 'Cambridge System'. The Cambridge system is the British education system adopted by a number of private school systems of the country. The entire system and the examinations are controlled by the University of Cambridge UK. Education in this system begins from Kindergarten and goes to O-level (grade 10) and A-level (grade 11, 12, and 13) before the children go the universities. These are the children of rich and affluent classes of the society because of the school systems' expensive fee structure. These children perform well in the universities. However, they have good knowledge about UK, its cities, geography, history, currency, and economy etc. but lack the proper knowledge and training about Pakistan, its cities, geography, history, currency, economy, etc. Hence, the children graduating from the Cambridge system are also not equipped with indigenous Pakistani knowledge to deal with Pakistan's specific issues and problems (Rahman 1997, Ishfaq 2009).

These four systems of education are responsible for creating classism in the society. Besides creating a number of social problems, these four systems are inadequate to meet the indigenous needs of Pakistan. Moreover, the systems are responsible for providing an education for the same people who are involved in training activities all over the country. However, things have started improving over the recent years. For example, according to a recent survey, the national education budget for 2016 was almost equal to the national defense budget that is, $\$ 7.5$ billion and $\$ 8.2$ billion respectively (Naviwala 2016). Similarly, the four provinces of Pakistan are now in a healthy competition to increase the education funding, train the teachers, provide free books to the population, make the education accessible to all, increase the student enrollment, and modernize the curricula (Husnain 2013, Ahmad, Rehman et al. 2014, Naviwala 2016, Siddiquei and Khalid 2017).

\subsection{Origins of Training in Pakistan}

The origins of training can be traced back to 1947 when Pakistan came into being. When the first National Education Conference took place in 1947, training was a major part of it. It was even recognized at that time that Pakistan would need skilled manpower to progress in future (Jahangir 2008). Thus, training has been a part of every education policy, national five-year plan, and literacy program since 1947. The need for training and skilled manpower has been recognized even more in recent years when the name of the Ministry of Education was changed to the Ministry of Education and Training in 2011. Today, three separate departments operate under the ministry among other departments. These departments are National Vocational and Technical Education Commission (NAVTEC), National Training Bureau, and Pakistan Manpower Institute (Husnain 2013). Moreover, a large number of training institutes have emerged over the years due to direct government intervention. These training institutes are called the training service providers (TSPs). Some of these TSPs have been shown in Appendix A.

Besides the government which has focused on filling the skill gaps in the economy and providing training to its population as a means of getting a job and being prosperous, the private sector and the multinational corporate giants have recently started playing their role. The private sector has established a training and consulting industry in the country since 1990s. The training and consulting industry include a large number of local companies as well as some renowned multinational consultancies like KPMG, Ernest \& Young, Boston Consulting Group (BCG), Deloitte, and Price Waterhouse Coopers. They have been offering training programs in almost every field of every industry including the education industry (both public and private sectors) (Head Marcher 2018). Some of the training and consulting firms that have been formed as a direct result of the intervention of the private sector has been shown in Appendix B.

Since 1990s, the training and consulting industry of Pakistan has been deeply engaged in training activities and training transfer. The industry does not seem to be much aware of the concept of training transfer itself though. Nor is there any evidence that anybody has attempted any indigenous training transfer research. There may be many reasons for that which need further investigation. For example, the industry may have been too much commercialized and busy in reaping the profits that nobody is measuring training transfer. Some researchers seem to be doing training transfer research but their research is mostly based on the assumption that the rate of training transfer is $15-30 \%$ (Najam and Bari 2017). Since the figure of $15-30 \%$ has already been proven to be unscientific (Fitzpatrick 2001, Saks 2002), it does not make any sense. Therefore, the following paragraphs would trace the evolution of training transfer in Pakistan as is being practiced in Pakistani organizations. Pakistani organizations in spite of practicing training transfer may not be fully aware of it.

\section{Training Transfer in Pakistan}

\subsection{Evolution of Training Transfer in Pakistan}

The term of training transfer seems to be unfamiliar in the Pakistani training and consulting industry as well as the Pakistani corporate sector. The concept of training transfer is known in Pakistani academia though, which has been explained in the next section. However, this section would trace the evolution of training transfer in Pakistan. This section will present various examples in which training was conducted and training transfer (both positive and negative) occurred but the awareness of the concept of training transfer itself was missing. 
Ellahi and Mushtaq (2011) conducted an empirical study to identify the factors that affected knowledge sharing among the bloggers of Pakistan. Their theoretical framework was based on three theories, which are: innovation diffusion theory, social capital theory, and theory of reasoned action. Surveys were used for quantitative data collection. Questionnaires were filled out by 120 bloggers. The results of the study were quite interesting. They found, "Relative advantage, attitude, and social interaction ties" play a significant role in knowledge sharing attitude of the bloggers. Considering that an intention to share knowledge itself is a predictor of knowledge behavior and "Relative advantage, attitude, and social interaction ties" could change the knowledge sharing attitude, the results can also shed some light on the concept of training transfer. Could "relative advantage, attitude, and social interaction ties" also be the precursors of positive training transfer? Further research is needed to prove that.

Another example is of National Agricultural Research Center (NARC) of Pakistan which is working on 17 agricultural research projects at the moment in collaboration with PARC Public Services Development Sector (PSDP). These projects are "American channel catfish, kitchen gardening a way to safe and nutritious vegetables, rehabilitation and strengthening of summer agricultural research station at Kaghan, capacity development of agri-extension services of KPK, Pak-China cooperation for agricultural research and development, upgradation of arid zone research institute (AZRI) as AZRC with establishments of new satellite research institutes at South \& North Waziristan Agencies (FATA), Indigenization of hybrid seed production for enhanced crop production, research for agricultural development program, horticultural research institute at Khuzdar, livestock research institute at Turbat, coastal agricultural research station at Bhawani, Baluchistan and other projects." According to Staff Reporter (2016), Research conducted in these institutions have no value until and unless the knowledge, skills, and attitudes are transferred from the scientific community to small farmers so that new scientific developments and innovations are used for the development of the agricultural sector. In spite of tremendous investments in the agricultural sector of Pakistan in the last 70 years, self-sufficiency in the food and agricultural sector is less than satisfactory. Maybe, the representatives of these scientific institutions should collaborate with farmers for transfer of knowledge, skills, and attitudes and thus a positive training transfer.

Another example is of the Auto industry of Pakistan. The auto industry of Pakistan currently has manufacturing and assembly plants of almost 17 companies; Toyota, Honda, Suzuki, and Hyundai being the major manufacturers. Pakistan produces almost 300,000 automobiles and commercial vehicles and 1.7 million motor bikes annually (Hussain 2018). Since 1979, a transfer of knowledge, skills, and attitudes have been taking place from the manufacturers to the local small vendors (MarketScreener 2017). This has resulted in a massive development of the local auto parts manufacturing vendors thus playing a major role in the overall development of the auto industry. Pakistan's auto industry which was mainly limited to the imported auto parts in their assembly plants in 1970s/80s now manufactures around 55 to $75 \%$ auto parts indigenously with the help of small vendors. This could not happen without the transfer of knowledge, skills, and attitudes from large manufacturers to small vendors in the form of training, workshops, and symposiums. Moreover, due to the same transfer of knowledge, skills, and attitudes, the auto industry is witnessing a boom in the last three years attracting even more auto manufacturers from around the world who want their share of the pie in the $\$ 3.6$ billion auto industry. Although the term of training transfer is not known in the auto industry, creating an awareness could enhance productivity and progress (ProPakistani 2015, MarketScreener 2017, Hussain 2018).

The emergency room trauma course delivered by International Committee of the Red Cross is another example of transfer of knowledge, skills, and attitudes in Pakistan. This course is meant to enhance the skills of the health professionals. The course is based on lectures, presentations, practical simulation exercises, disaster preparedness, role play, drills, and techniques of airway management by bag and masking etc. The course seems to be invaluable for the emergency health professionals but the extent of the knowledge, skills, and attitudes gained during this course and transferred to the job efficiency is unknown. That is why training transfer is an important concept that needs to be adopted in every circle of Pakistan (International Committee of the Red Cross 2018).

Yet another example is IFC World Bank, which in collaboration with Bles Dairies Consultancy Netherlands. The agency has trained 50 Dairy Development Executives (DDEs) in Pakistan in 2018. Although these executives had a good theoretical knowledge, they lacked practical experience. Based on the concept of learning by doing, these dairy development executives were trained in their premises in Pakistan and thus a positive transfer of knowledge, skills, and attitudes took place (Bles Dairies 2018).

By looking at the above examples, it can be seen that training transfer is a phenomenon which has been prevalent since the birth of Pakistan in 1947. Training has been occurring and the transfer of knowledge, skills, and attitudes have been taking place. The only difference is that people are not aware of the concept of training transfer. It is for this reason that Pakistan needs to understand the concept of training transfer. For example, with an awareness of training transfer, the activities relating to the transfer of knowledge, skills, and attitudes can be streamlined, jobs can be made more productive, and training and training transfer can play their roles in the economic development of Pakistan 


\subsection{Current Trends in Training Transfer Research in Pakistan}

Although training is a fairly old concept in Pakistan as organizations have been providing training to their employees since the birth of Pakistan in 1947, research on training transfer started surfacing only over the last decade. Training transfer research conducted in Pakistan has not proven to be very useful. The reasons are twofolds. Firstly, training transfer research in Pakistan has been based on the premise that the rate of training transfer is only $15-30 \%$. The rate of training transfer, assumed to be $10 \%$ in the decades of $1980 \mathrm{~s}$ and $1990 \mathrm{~s}$ and $15-$ $30 \%$ today in 2018, is unscientific, unproven, and American based (Fitzpatrick 2001, Saks 2002). The rate of training transfer as only 10\% was first published by Georgenson (1982). Georgenson penned the rate of training transfer as $10 \%$ only as an estimate or as a casual language used by a manager. He did not know that his figure of $10 \%$ would be taken so literally by the future researchers (Saks 2002). Therefore, continuing to use the figures of $10 \%$ or $15-30 \%$ would not only be misleading but inaccurate (Salas and Cannon-Bowers 2001). Secondly, there is no official data available in Pakistan on how much Pakistan spends on training every year. The data is important to get an estimate on how much Pakistan is losing annually in financial terms because of the transfer problem.

Training transfer research in Pakistan has been mostly conducted through case studies of organizations in the public and private sectors. For example, Khalid, Ashraf, and Rehman (2012) studied a link between Kirkpatrick (KP) and input, process and product (CIPP). They presented a training evaluation framework to enhance training transfer in public sector organizations of Pakistan. This study found out that a pre-training context was imperative for training transfer. This paper shed light on the overall concept of training transfer giving special importance to the training transfer context and training evaluation to achieve positive training transfer.

Similarly, Aslam (2013) conducted an analysis of the professional development practices of school teachers in Pakistan using a mixed methods approach. Khalid, Hanif et al. (2017) also utilized a mixed methods research to explore the challenges of training transfer in a government organization called NADRA. Amin, Saeed et al. (2013) also used mixed methods research with a sample size of 200 education sector employees to explore the impact of employee training on job performance. Using a case study of a government department, Cheema and Syed (2014) used content analysis to review training transfer in Pakistan from a critical lens and identified issues associated with training transfer in almost all the sectors in the country. They also took a government sector department as a case study. Imran and Tanveer (2015) used the banking sector as an example and utilized mixed methods approach to find out the impact of training and development on the performance of employees. Qureshi, Bhutto et al. (2017) measured the factors that affect training transfer using SSGC as a case study. SSGC is a government agency. They used survey instruments like questionnaires and utilized SPSS as a quantitative data analysis tool. Other researchers have used quantitative research approaches to determine the effects of various factors on training transfer. For example, Ahmed, Abdul Majid et al. (2015) measured the impact of reward and accountability on training transfer. Similarly, Ishaq and Mumtaz (2014) measured the effects of organizational context on training transfer.

\section{To Be Continued ...}

This section discusses future research, summary and conclusion. The three parts; future research, summary and conclusion need to be further discussed and researched, hence, the title of the topic "To be Continued". In future research, research needed in training and training transfer has been highlighted. Since this paper is on the origin, evolution, and practice of training transfer in Pakistani organizations, other associated prospective research topics have also been taken into account such as education.

The summary and conclusion part summarize the paper and draws proper conclusions based on the above discussion.

\subsection{Future Research}

Training transfer is a new concept in Pakistan. There is a need to introduce this topic in Pakistani public and corporate sectors and academia. According to Baldwin, Ford et al. (2009), training transfer is the acquisition of knowledge, skills, and attitudes from a training and transferring it to a job efficiency or productivity. Knowledge and understanding of training transfer make training accountable. For example, if training is conducted in a specific field, training transfer informs us how much of that training has actually been translated into job efficiency and productivity. Currently, Pakistani public and corporate sectors seem to be unaware of the concept of training transfer. Since some research publications on training transfer has surfaced in the last decade, Pakistani academia seems to be aware of the concept; although in a very limited term. In academia, training transfer seems to be just another topic of research that can be used for publications to add to the academic profiles of the faculty. Pakistani training and consulting industry that has experienced an explosive growth in the last couple of decades also seem to be too much focused on the commercial aspects of training, completing ignoring the results and benefits of their training. Therefore, various gaps exist in training transfer research and 
practice in Pakistani organizations. Some of these gaps and future research are provided below:

1. The four systems of elementary and high school education discussed above are creating various social and research problems in the country besides creating classism in the society. For example, the four systems of education are creating a tiny population of Cambridge educated people (completely unaware of Pakistani issues \& problems) to govern a massive population that is aware of the Pakistani issues and problems but unequipped educationally to deal with them. The four systems of education are also producing such training transfer researchers who are unable to decipher a simple fact that training transfer issues in Pakistan could not be the same as in the United States. Future research is very much needed on the relationship between education and training. Moreover, there is also a need to indigenize and modernize the Pakistani education system from the elementary level to the university level making it equal and accessible for all. There is a need to produce high quality indigenous curricula for primary (grade 5), high school (grade 10), and college (grade 12). These curricula should be approved by the Ministry of Education and Training and it should be made mandatory for all school systems.

2. There should be some proper checks on the training and consulting industry of Pakistan. That includes training and consulting firms as well as independent trainers and consultants. They should be made accountable for the training they conduct. Moreover, ways and means should be devised to measure the rate of training transfer. Therefore, there is a need for research to explore the relationship between training conducted and results achieved in Pakistani organizations. In other words, Pakistan needs an extensive research on training transfer and its implications on Pakistani organizations.

3. There is a need for a research on the training conducted by more than 50 training service providers (TSPs) in Pakistan and the rate of training transferred that has occurred as a result.

4. There are no official data available in Pakistan on how much Pakistan spends on training every year. The data are important to get an estimate on how much Pakistan is losing annually in financial terms because of the transfer problem. Therefore, there is a need for research on the annual expenditure of Pakistani training and consulting industry.

5. Highly reputable research institutes, like Pakistan Institute of Development Economics, (PIDE) discuss and publish reports, manuscripts, articles, and books on all kinds of subjects ranging from economy and development to education, environment, and policy making but they did not discuss human resources, training, and training transfer. In a developing country like Pakistan, development economics deals with the economic aspects of the development process such as economic growth, structural change, and improving the potential of mass population through improvements in education, training, and work conditions etc. Research institutes such as PIDE seems to be unaware of the role of training and training transfer in development. There is a need for a research on the relationship between training and economic development in developing countries.

6. Ellahi and Mushtaq (2011) conducted an empirical study to identify the factors that affect knowledge sharing among the bloggers of Pakistan. Their theoretical framework was based on three theories; innovation diffusion theory, social capital theory, and theory of reasoned action. Surveys were used for quantitative data collection. Questionnaires were filled out from 120 bloggers. The researchers found out "relative advantage, attitude, and social interaction ties" play a significant role in knowledge sharing attitude of the bloggers. Considering that an intention to share knowledge itself is a predictor of knowledge behavior and "relative advantage, attitude, and social interaction ties" could change the knowledge sharing attitude, the results can also shed some light on the concept of training transfer. Could "relative advantage, attitude, and social interaction ties" also be the precursors of positive training transfer? Further research is needed to explore this issue.

7. The economic survey of Pakistan is published every year by the government of Pakistan. It is a 300page document and it usually has 16 chapters. These chapter are Growth and Investment, Agriculture, Manufacturing and Mining, Fiscal Development, Money and Credit, Capital Markets \& Corporate Sector, Inflation, Trade and Payments, Public Debt, Education, Health and Nutrition, Population, Labor Force and Employment, Transport and Communications, Energy, Social Safety Nets, and Climate Change. There is no chapter on training or training transfer. There is a need for a research on the level of awareness about training, training transfer, and their role in the economic development of Pakistan, in the public and corporate sectors as well as academia. This kind of research can then provide recommendations to the economic survey of Pakistan on the inclusion of a chapter on training and training transfer.

8. Statistical Bureau of Pakistan publishes monthly bulletins of statistics. "The bulletin of statistics, monthly publication provides important statistics in respect of social, economic and financial sectors of the economy at aggregate as well as sectoral levels. The bulletin contains data relating to population, national accounts, agriculture, manufacturing, prices, balance of payments, public finance, education, energy and mining, foreign economic assistance, foreign trade, health, insurance, labor, transport and 
communication, social and culture etc. It also provides different types of indices on agriculture, manufacturing, prices, trade and labor productivity" (Akhtar 2018). The bulletin provides limited information on training within the education segment which shows that training is given a low priority. A research on the awareness, significance, and the role of training in the economic development of Pakistan should be able to provide recommendations to the Statistical Bureau of Pakistan on adding training and training transfer in their agenda as important enough to provide statistical data on.

\subsection{Summary \& Conclusion}

This paper is about the origins, evolution, current state and trends in training transfer research and practice in Pakistani organizations. The paper begins with a discussion on education and training. The premise of the discussion between education and training is that education is the base of training. An individual's learning takes place because of both education and training. The difference is that education is broad, general, and knowledgebased while training is narrow, specific, and skill-based. Therefore, it is indicated in this paper that an understanding of the Pakistani education system is vital for the proper understanding of the origins, evolution, current state, and trends in training transfer research and practice in Pakistani organizations.

The next section in the paper discusses the evolution of education and training in Pakistan and explains the four systems of education in Pakistan at the primary (grade 5), high school (grade 10), and college (grade 12) levels. The four systems of education are Madrasa, Urdu medium, English medium, and Cambridge. This discussion concludes that besides creating various social problems and classism in the society, these four systems of education are also producing training transfer researchers whose publications seem to follow the western research without realizing that training transfer issues might be entirely different in Pakistan than the western world.

In the next section, the paper explores the origins of training in Pakistan. While exploring the origins of training in Pakistan, the section provides a detailed account on the training and consulting industry of Pakistan, both public and private sectors. After that, the paper traces the evolution of training transfer in Pakistan. The section presents various examples in which training was conducted and training transfer (both positive and negative) occurred but the awareness of the concept of training transfer itself was missing.

The next section discusses the trends of training transfer research in Pakistan. This section not only discusses the training transfer research conducted by various Pakistani researchers but also explains why the concept of training transfer is important. This paper then ends with some suggestions for further research and a section on summary and conclusion.

\section{APPENDIX A}

1. Advanced Studies in Engineering (CASE).

2. ASK Development.

3. Association of Business Executives (ABE).

4. Astute Associates.

5. Business Beam (Pvt.) Limited.

6. Center for Management Development (CMD).

7. Creative Dimensions (CMD).

8. DAN-SOL.

9. EECS Asia.

10. Gems and Gemological Institute of Pakistan (GGIP).

11. Gems and Jewelry Training and Manufacturing Centre (GJTMC), Lahore.

12. Globe Touch Co. UK.

13. Highly Keen.

14. ICIL (PVT). Limited.

15. Institute of Rural Management (IRM).

16. Institute of Skills and Enterprise International (ISEI).

17. INTEK Solution.

18. IKTAR Consulting.

19. Kinverg Management Consulting.

20. Leading Edge.

21. Learning Institute of Training and Enlightenment.

22. MEET (Managers, Executives, Entrepreneurs' Trainers) - Pakistan.

23. Narejo Human Resources.

24. Net Sol Technologies Institute.

25. Nur Concepts.

26. Occupational Safety and Loss Prevention (OSALP). 
27. Occupational Training Institute (OTI).

28. One Tree Hill (Private) Limited.

29. Pakistan Industrial Technical Assistance Centre (PITAC).

30. Pakistan Institute of Development Economics (PIDE).

31. Pakistan Institute of Management (PIM).

32. Pakistan Institute of Quality Control (PIQC).

33. Paramount Consulting.

34. Punjab Vocational Training Council (PVTC).

35. Quality Concerns.

36. Quality Management Systems 9000.

37. Radius Academy for Corporate Training.

38. Rays Training \& Development Systems.

39. SAARC Human Resource Development Centre.

40. STEP Institute of Professional Development.

41. Sloan.

42. Tariq Mustafa Ramzan \& Co. (TMRC).

43. Technical Education \& Vocational Training Authority (TEVTA).

44. Technology Upgradation and Skill Development Company (TUSDEC).

45. The British Council Pakistan.

46. Time Lenders.

47. Trade Development Authority of Pakistan (TDAP).

48. XAVOR

49. ZAS MultiVision.

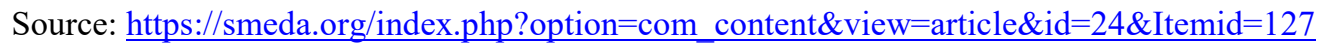

\section{Training Service Providers (TSPs) established due to Government Intervention}

\section{APPENDIX B}

1. Aon Consulting

2. BearingPoint

3. Boston Consulting Group (BCG)

4. CDM Consulting

5. Computer Associates

6. Computer Sciences Corporation (CSC)

7. Deloitte Consulting

8. $\quad$ Ernst \& Young

9. Grant Thornton

10. KPMG Consulting

11. Manpower

12. PriceWaterhouseCoopers $(\mathrm{PwC})$

13. IMS Health

14. Unisys Consulting

15. NUST Consulting

Source: https://www.consultingcase101.com/list-of-consulting-firms-in-islamabad-pakistan/

\section{Training Service Providers (TSPs) established due to Private Sector Intervention}

\section{References}

Ahmad, I., K.-u. Rehman, A. Ali, I. Khan and F. A. Khan (2014). "Critical analysis of the problems of education in Pakistan: Possible solutions." International Journal of Evaluation and Research in Education (IJERE) 3(2): 79-84.

Ahmed, U., A. Abdul Majid, M. L. Mohd Zin, W. Phulpoto and W. A. Umrani (2015). "Role and impact of reward and accountability on training transfer." Business and Economics Journal 7(1): 1-6.

Akhtar, S. (2018). Monthly bulletin of statistics, May 2018. G. o. P. Pakistan Bureau of Statistics. Islamabad, Pakistan Bureau of Statistics.

Amin, A., R. Saeed, R. N. Lodhi, Mizna, Simra, A. Iqbal and R. Tehreem (2013). "The Impact of employees training on the Job performance in education sector of Pakistan." Middle-East Journal of Scientific Research 17(9): 1273-1278.

Aslam, H. D. (2013). "Analysis of professional development practices for school teachers in Pakistan: A 
comparative case study of public and private schools of Pakistan (Punjab)." International Journal of Human Resource Studies 3(4): 311-326.

Baldwin, T. T., J. K. Ford and B. D. Blume (2009). Transfer of training 1988-2008: An updated review and new agenda for future research. International review of industrial and organizational psychology. G. P. Hodgekinson and J. K. Ford. Chichester, UK, Wiley. 24: 41-70.

Bengali, K. (1999). History of education policy making and planning in Pakistan. Islamabad, Pakistan, Sustainable Development Policy Institute (SDPI).

Bles Dairies. (2018). "Learning by doing in Pakistan: Final phase." Retrieved October 26, 2018, from https://www.bles-dairies.nl/learning-by-doing-in-pakistan-final-phase/.

Butt, M. Q. and M. S. Khalid (2017). "The role of madrasa education in inter-cultural and cross-cultural exchange." Bulletin of Education and Research 39(1): 61-74.

Chaudhry, M. A. (2017). National education policy 2017-2025. G. o. P. Ministry of Federal Education and Professional Training. Islamabad, Pakistan, Government of Pakistan.

Cheema, F.-e.-A. and N. A. Syed (2014). "Issues of transfer of training from the training houses to the line department: A case of government sector department in Pakistan." IBT Journal of Business Studies 9(1): $150-158$

Dildar, S. M., N. N. Saif and A. Naz (2016). Review of Educational Policies of Pakistan: Planning and Implication flows. First International Conference 5Es, Department of Education, University of Sargodha, Pakistan.

Ellahi, A. A. and R. Mushtaq (2011). "Probing factors affecting knowledge sharing behavior of Pakistani bloggers." The Electronic Journal of Information Systems in Developing Countries 45(1): 1-14.

Fitzpatrick, R. (2001). "The strange case of the transfer of training estimate." The Industrial-Organizational Psychologist 39(2): 18-19.

Georgenson, D. L. (1982). "The problem of transfer calls for partnership." Training \& Development Journal 36(10): 75 .

Head Marcher. (2018). "Training and development trends in Pakistan (2016-2017)." Retrieved October 20, 2018, from http://www.headmarcher.com/training-and-development-trend-in-pakistan-2016-2017/.

Husnain, Z. (2013). Pakistan economic survey 2013-14. G. o. P. Ministry of Finance. Islamabad, Pakistan, Ministry of Finance, Government of Pakistan: 129-144.

Hussain, A. (1998). Ninth five year plan: 1998-2003. W. G. o. P. Alleviation. Islamabad, Pakistan, Working Group on Poverty Alleviation, Planning Commission.

Hussain, B. (2018). The changing landscape and face of Pakistan's auto sector. The Express Tribune. Karachi.

Imran, M. and A. Tanveer (2015). "Impact of training and development on employees' performance in banks of Pakistan." European Journal of Training and Development Studies 3(1): 22-44.

International Committee of the Red Cross. (2018). "Pakistan: Cultivating skills for enhanced trauma care." Retrieved October 28, 2018, from https://www.icrc.org/en/document/pakistan-cultivating-skill-enhancedtrauma-care.

Ishaq, H. M. and T. Mumtaz (2014). Impact of employee behaviour and organizational support on training transfer process. Human Capital without Borders: Knowledge and Learning for Quality of Life. Portorož, Slovenia.

Ishfaq, U. (2009). "A study of the rapid growth of "O" and "A" levels of education in Pakistan." Contemporary Issue in Education Research 2(1): 75-80.

Jahangir, K. (2008). Management of higher education reforms in Pakistan: An implementation perspective, Utrecht School of Governance, Utrecht University, Netherlands.

Khalid, M., M. Ashraf and C. A. Rehman (2012). "Exploring the link between Kirkpatrick (KP) and context, input, process and product (CIPP) training evaluation models, and its effect on training evaluation in public organizations of Pakistan." African Journal of Business Management 6(1): 274-279.

Khalid, M., A. Hanif and U. Laila (2017). "Transfer of training \& the challenges: NADRA A case study." International Review of Management and Business Research 6(1): 274-288.

MarketScreener. (2017). "Honda Atlas Cars Pakistan : HACPL to enhance, transfer knowledge and expertise to local vendors." Retrieved October 27, 2018, from https://www.marketscreener.com/HONDA-ATLASCARS-PAKISTA-6492750/news/Honda-Atlas-Cars-Pakistan-HACPL-to-enhance-transfer-knowledge-andexpertise-to-local-vendors-25449343/.

Najam, A. and F. Bari (2017). Pakistan national human development report 2017. United Nations Development Programme, Islamabad, Pakistan, United Nations Development Programme, Pakistan.

Nasir, Z. M. and H. Nazli (2000). Education and Earnings in Pakistan. Pakistan Institute of Development Economics Islamabad, Pakistan Institute of Development Economics.

Naviwala, N. (2016). Pakistan's education crises: The real story. Asia Program, Wilson Center, Islamabad, Pakistan, Asia Program, Wilson Center: 1-36. 
Nelson, E. (2018). "Urdu medium educatiion in India and Pakistan." Retrieved October 15, 2018, 2018, from https://foreigncy.us/urdu-medium-education-in-india-and-pakistan/.

Newstrom, J. W. (1984). A role-taker/time differentiated integration of transfer strategies. 1984 meeting of the American Psychological Association (APA), Toronto, Ontario.

ProPakistani. (2015). "Automotive industry's contribution to Pakistan." Retrieved October 27, 2018, from https://propakistani.pk/2015/08/12/automotive-industrys-contribution-to-pakistan-infographic/.

Qureshi, Q.-u.-A., A. Bhutto and R. A. Tunio (2017). "Factor affecting the transfer of training at the workplace: Case study of SSGC Ltd, Pakistan." International Journal of Academic Research in Business and Social Sciences 7(2): 357-370.

Rahman, T. (1997). "The medium of instruction controversy in Pakistan." Journal of Multilingual \& Multicultural Development 18(2): 145-154.

Rahman, T. (2010). Language and children's education in Pakistan, USAID. 27.

Sajjad, F. (2013). "Reforming madrasa education in Pakistan: Post 9/11 perspectives." Journal of Islamic Thought and Civilization 3(1): 104-121.

Saks, A. (2002). "So What is a Good Transfer of Training Estimate? A Reply to Fitzpatrick." The IndustrialOrganizational Psychologist 39: 28-30.

Salas, E. and J. A. Cannon-Bowers (2001). "The science of training: A decade of progress." Annual Review of Psychology 52(1): 471.

Sarmad, K., F. Husain and G. M. Zahid (1989). The education sector in Pakistan. G. Chaudhry and K. Sarmad. Pakistan Institute of Development Economics Islamabad, Pakistan Institute of Development Economics.

Shakoor, A., M. Azeem, A. H. Dogar and Z. Khatoon (2011). "1947-2008 Evaluation of elementary education in Pakistan." International Journal of Humanities and Social Sciences 1(15): 270-276.

Siddiquei, N. L. and R. Khalid (2017). "Emerging trends of E-learning in Pakistan: Past, present and future." International Journal of Law, Humanities \& Social Science 2(1): 20-35.

Staff Reporter (2016). Scientists urged to transfer knowledge to small farmers. Pakistan Observer. Islamabad, Pakistan Observer.

Tight, M. (2003). Key concepts in adult education and training. London, Routledge.

Wexley, K. N. and G. P. Latham (1981). Developing and training human resources in organizations. Glenview, IL, Scott Foresman. 